\section{Commentary: Coronary artery bypass grafting in midrange ejection fraction: Charting unknown waters}

\author{
Nicolas H. Pope, MD, ${ }^{a}$ and Arman Kilic, $\mathrm{MD}^{\mathrm{b}}$
}

Ischemic heart failure with a reduced ejection fraction (HFrEF) is a common but morbid consequence of untreated coronary disease. The definition of HFrEF as those patients with a left ventricular ejection fraction (LVEF) $<40 \%$ leaves a cohort of patients in whom LVEF exceeds $40 \%$ but is lower than the normal value of $55 \%$. Outcomes following surgical coronary revascularization in patients with HFmrEF (HF with mid-range LVEF: $40 \%$ to $55 \%$ ) remain incompletely reported.

How best to characterize patients with HFmrEF remains a point of discussion in the literature. Previous studies have found that HFrEF patients closely resemble patients with heart failure with preserved ejection fraction (HFpEF) in age and comorbidities. ${ }^{1}$ Importantly however, HFpEF may represent a distinct entity in which diastolic dysfunction leads to heart failure symptoms. ${ }^{2} \mathrm{HFmrEF}$ patients have been shown to have coronary artery disease at a rate more similar to cohorts of HFrEF patients. ${ }^{3}$ But how do HFmrEF patients compare to patients with severe coronary disease without clinical symptoms of heart failure?

In this issue of the Journal, Deo and colleagues ${ }^{4}$ present a retrospective examination of isolated coronary artery bypass grafting (CABG) in this cohort, with outcomes including length of stay, rehospitalization for heart failure and mortality. In their study, patients with HFmrEF more closely resembled patients with HFrEF in both 10-year

From the a Division of Cardiothoracic Surgery, Medical University of South Carolina, Charleston, SC; and ${ }^{\mathrm{b}}$ Division of Cardiac Surgery, The University of Pittsburgh Medical Center, Pittsburgh, Pa.

Disclosures: Dr Kilic reported serving on the Medical Advisory Board for Medtronic. Dr Pope reported no conflicts of interest.

The Journal policy requires editors and reviewers to disclose conflicts of interest and to decline handling or reviewing manuscripts for which they may have a conflict of interest. The editors and reviewers of this article have no conflicts of interest.

Received for publication Jan 20, 2021; revisions received Jan 20, 2021; accepted for publication Jan 21, 2021; available ahead of print Jan 21, 2021.

Address for reprints: Arman Kilic, MD, University of Pittsburgh Medical Center, 200 Lothrop St, Suite C-700, Pittsburgh, PA 15213 (E-mail: kilic.arman@gmail.com). J Thorac Cardiovasc Surg 2023;165:162-3

$0022-5223 / \$ 36.00$

Copyright (c) 2021 by The American Association for Thoracic Surgery

https://doi.org/10.1016/j.jtcvs.2021.01.079

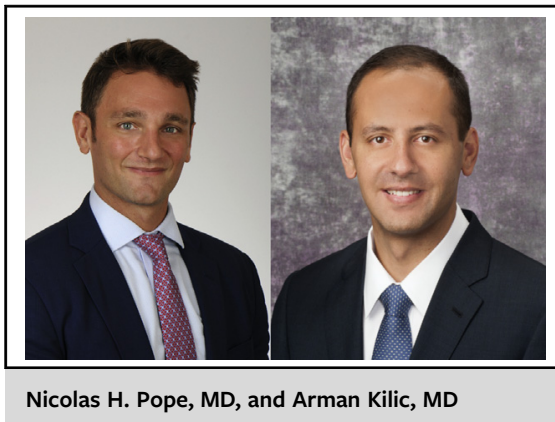

CENTRAL MESSAGE
Patients with mid-range ejection
fraction ( $40 \%$ to $55 \%$ ) are
understudied. This analysis shows
that coronary artery bypass
grafting (CABG) surgery in pa-
tients with mid-range ejection
fraction is associated with higher
mortality and readmission risk
than CABG in patients with
normal ejection fraction.

adjusted mortality (odds ratio [OR], 1.31 for HFmrEF vs 1.46 for $\mathrm{HFrEF}$ ) and rehospitalization for heart failure (OR, $22.4 \%$ vs $30.5 \%$ ) compared with patients with normal ventricular function.

Importantly, the authors point out that patients with HFmrEF were less likely to be discharged on mainstays of goal-directed medical therapies, including angiotensinand aldosterone-blocking agents. Although many of the studies that reported efficacy of these agents excluded patients with HFmrEF, the rate of hospital readmission for heart failure after CABG may indicate room for improvement in managing heart failure in these patients. ${ }^{5-7}$ Further work is needed to better characterize optimal management of patients with HFmrEF.

Another factor relevant to the discussion of $\mathrm{CABG}$ patients with HFmrEF is the trajectory of their cardiac function, clinical heart failure, and subsequent need for advanced heart failure therapy, such as cardiac transplantation or implantation of a durable left ventricular assist device. Whether the aforementioned medical therapy can favorably adjust these trajectories remains to be elucidated. Early consultation with an advanced heart 
failure cardiologist may be an important step in improving outcomes in this patient cohort. These benefits may relate not just to active medical management of the patient, but also to the ability to longitudinally follow the patient and assess their need for more advanced therapy.

\section{References}

1. Hsu JJ, Ziaeian B, Fonarow GC. Heart failure with mid-range (borderline) ejection fraction: clinical implications and future directions. JACC Heart Fail. 2017;5: 763-71.

2. Lee DS, Gona P, Vasan RS, Larson MG, Benjamin EJ, Wang TJ, et al. Relation of disease pathogenesis and risk factors to heart failure with preserved or reduced ejection fraction: insights from the Framingham Heart Study of the National Heart, Lung, and Blood Institute. Circulation. 2009;119:3070-7.
3. Cheng RK, Cox M, Neely ML, Heidenreich PA, Bhatt DL, Eapen ZJ, et al Outcomes in patients with heart failure with preserved, borderline, and reduced ejection fraction in the Medicare population. Am Heart J. 2014; 168:721-30.

4. Deo SV, Sundaram V, Sahadevan J, Elgudin Y, Kilic A, Cmolik B, et al. Outcomes of coronary artery bypass grafting in patients with heart failure with a midrange ejection fraction. J Cardiovasc Thorac Surg. 2023;165:149-58.e4.

5. SOLVD Investigators, Yusuf S, Pitt B, Davis CE, Hood WB, Cohn JN. Effect of enalapril on survival in patients with reduced left ventricular ejection fractions and congestive heart failure. N Engl J Med. 1991;325:293-302.

6. McMurray JJV, Packer M, Desai AS, Gong J, Lefkowitz MP, Rizkala AR, et al. Angiotensin-neprilysin inhibition versus enalapril in heart failure. $N$ Engl J Med. 2014:371:993-1004.

7. Packer M, Anker SD, Butler J, Filippatos G, Pocock SJ, Carson P, et al. Cardiovascular and renal outcomes with empagliflozin in heart failure. N Engl J Med. 2020; $383: 1413-24$. 